\title{
The Thermodynamic Effect of Shallow Groundwater on Temperature and Energy Balance at Bare Land Surface
}

\author{
F. Alkhaier ${ }^{1}, \mathrm{G}$. N. Flerchinger ${ }^{2}$ and Z. Su ${ }^{1}$ \\ ${ }^{1}$ Department of water resources Faculty of Geo-Information \\ Science and Earth Observation, University of Twente \\ ${ }^{2}$ Northwest Watershed Research Center, United States Department of Agriculture \\ ${ }^{1}$ The Netherlands \\ ${ }^{2} U S A$
}

\section{Introduction}

Within the foregoing half century, several studies debated over the effect that shallow groundwater has on land surface temperature (Myers \& Moore, 1972; Huntley, 1978; Quiel, 1975). As land surface temperature is a key factor when the process of energy and water exchange between land surface and atmosphere occurs, we can presume that shallow groundwater naturally affects the entire surface energy balance system.

Shallow groundwater affects thermal properties of the region below its water table. Further on, it alters soil moisture of the zone above its water table which results in affecting its thermal properties, the magnitude of evaporation, albedo and emissivity. Hence shallow groundwater affects land surface temperature and the surface energy balance in two different ways; direct and indirect (Figure 1). The direct way (henceforth referred to as thermodynamic effect) is through its distinctive thermal properties which make groundwater acts as a heat sink in summer and a heat source in winter, and affects heat propagation within soil profile. The indirect way is through its effect on soil moisture above water table and its related effects (i.e. evaporation, soil thermal properties of vadose zone, land surface emissivity and albedo).

Studies that investigated the thermodynamic effect commenced by the work of Kappelmeyer (1957), who could successfully use temperature measurements conducted at shallow depth $(1.5 \mathrm{~m})$ to locate fissures carrying hot water from deep groundwater. Birman (1969) also found a direct relationship between shallow ground temperature and depth to groundwater. Works by Cartwright $(1968,1974)$, Bense \& Kooi, 2004, Furuya et al. (2006) and also works by Takeuchi $(1980,1981,1996)$ and Yuhara (1998) cited by Furuya et al. (2006) showed that soil temperature measurements at some depth $(0.5-2 \mathrm{~m})$ depth were useful for locating shallow aquifers in summer and winter and also for determining the depth of shallow groundwater and the velocity and direction of its flow.

On the other hand, a number of studies considered the indirect effect of shallow groundwater in terms of its effect on soil moisture of the vadose zone and at land surface (York et al., 2002; Liang \& Xie, 2003; Chen \& Hu, 2004; Yeh et al., 2005; Fan et al., 2007; 
Gulden et al., 2007; Niu et al., 2007; Lo et al., 2008; Jiang et al., 2009). They linked shallow aquifers to land surface and atmospheric models through the effect of soil moisture in terms of its mass on the water budget and evapotranspiration at land surface.

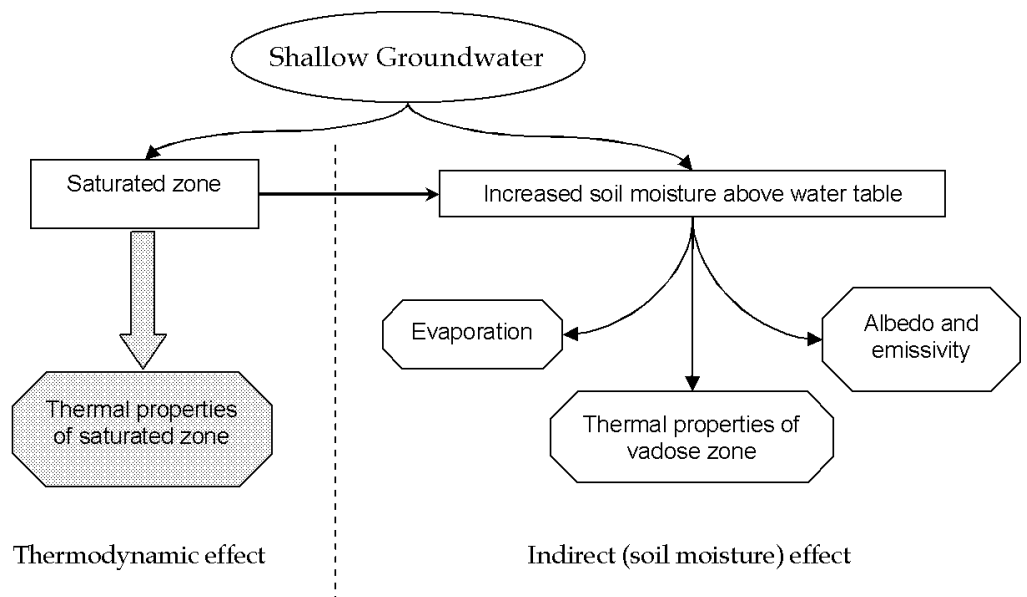

Fig. 1. Schematic description of the two different effects of groundwater

The effect of shallow groundwater on soil temperature has inspired some researchers to consider utilizing thermal remote sensing in groundwater mapping. For instance, Myers \& Moore (1972) attempted to map shallow groundwater using the brightness temperature of land surface retrieved from an airborne radiometer. They found a significant correlation between land surface temperature and depths to groundwater in a predawn imagery of 26 August 1971. Huntley (1978) examined the utility of remote sensing in groundwater studies using mathematical model of heat penetration into the soil. Nevertheless, his model was not sophisticated enough to consider groundwater effect on surface energy fluxes (i.e. latent, sensible and ground heat fluxes), besides, it neglected totally the seasonal aspect of that effect. In 1982, Heilman \& Moore (1982) showed that radiometric temperature measurements could be correlated to depth to shallow groundwater, but they recommended developing a technique for distinguishing water table influences from those of soil moisture to make the temperature method of value to groundwater studies.

Recently, Alkhaier et al. (2009) carried out extensive measurements of surface soil temperature in locations with variant groundwater depth, and found good correlation between soil temperature and groundwater depth. However, they also doubted about the cause of the discovered effect; was it due the indirect effect throughout soil moisture or was it because of the thermodynamic effect of the groundwater body. Furthermore, they suggested building a comprehensive numerical model that simulates the effect of shallow groundwater on land surface temperature and on the different energy fluxes at land surface. Studies that dealt with the thermodynamic effect (Kappelmeyer, 1957; Cartwright, 1968, 1974; Birman, 1969; Furuya et al., 2006) explored that effect on soil temperature at some depth under land surface. By their deep measurements, they aimed at eliminating the indirect effect. Consequently they totally missed out considering that effect on temperature and energy fluxes at land surface. On the other hand, studies that considered the indirect 
effect (York et al., 2002; Liang \& Xie, 2003; Chen \& Hu, 2004; Yeh et al., 2005; Fan et al., 2007; Gulden et al., 2007; Niu et al., 2007; Lo et al., 2008; Jiang et al., 2009) were centered on the effect of soil moisture in terms of water mass and passed over the effect on soil thermal properties. Furthermore, studies which considered groundwater effect to be utilized in remote sensing applications (Huntley, 1978; Heilman \& Moore's, 1982; Alkhaier et al., 2009) were faced with the problem of separating the effect of groundwater from that of soil moisture, there was hardly any sole study that conceptually and numerically discriminated the thermodynamic effect from the effect of soil moisture.

Quantifying the different aspects of groundwater effect can result in better understanding of this phenomenon. Further, this may advance related surface energy balance studies and remote sensing applications for shallow aquifers. This chapter centers on the thermodynamic effect which was separated out numerically from the other effects. We undertook to answer these questions: does shallow groundwater affect land surface temperature and surface energy balance at land surface regardless of its effect on soil moisture above water table? What are the magnitude and the pattern of that effect? And is that effect big enough to be detected by satellites?

With the aid of numerical modeling which progressed in complexity, we show in this chapter how the presence of groundwater, through its distinctive thermal properties within the yearly depth of heat penetration, affects directly land surface temperature and the entire surface energy balance system thereby. By applying different kinds of boundary conditions at land surface and changing the level of water table within the soil column, we observed the difference in temperature and the energy fluxes at land surface.

\section{Numerical experiments}

Two numerical experiments were implemented in this study. The first was simple and conducted using FlexPDE (PDE Solutions Inc.), a simulation environment which makes use of finite element technique to solve differential equations. The aim behind this experiment was to 1) prove that the thermodynamic effect of groundwater does indeed reach land surface and 2) to show that it is not appropriate to simply assign one type of boundary condition at land surface, and to explain that solving the entire surface energy balance at land surface is inevitable to realize groundwater effect. The entire surface energy balance system was simulated in the second experiment which was implemented using a well known land surface model code (Simultaneous Heat and Water model, SHAW, Flerchinger, 2000).

Initially we portray the common features among the different experiments; afterwards we describe the specific conditions for each experiment. Although the experiments were implemented within different numerical environments, they were performed using similar 1-D soil profiles. The lower boundary condition in both experiments was set at a depth of $30 m$ (deeper than the yearly penetration depth of heat) as a fixed temperature which is the mean annual soil temperature. Each experiment involved five simulations that were performed first for a profile with no groundwater presence, then for cases where groundwater perched at 0.5, 1, 2 and 3 meters respectively.

Groundwater presence within the soil column was introduced virtually through assigning different values of both thermal conductivity and volumetric heat capacity of saturated soil to the region below the imaginary water table. Rest of the soil in the profile was assigned the values of thermal properties for dry soil. 
In the first experiment, water transfer was not considered at all; heat transfer was the only simulated process. In the second experiment water movement and soil moisture transfer were simulated normally, because SHAW simulates both heat and water transfers simultaneously and its forcing data include rainfall. Yet we adjusted the SHAW code in a way that soil thermal properties were independent from soil moisture, and were fixed and predefined as the values adopted in the first two experiments. In that way groundwater was not present actually within soil profile in SHAW simulation rather than it did exist virtually through the different thermal properties of the two imaginary zones (saturated and dry zones). By doing so, we guaranteed the harmony among the two experiments and also ensured separating the thermodynamic effect from the effect of soil moisture.

The same soil thermal properties of virtually saturated and dry zones within soil profiles were used in all experiments. Values of thermal conductivity were adopted as the values for standard Ottawa sand measured by Huntley (1978), who conducted similar modeling experiment. Volumetric heat capacity values were calculated using the expression of de Vries (1963). Accordingly, we used in all of our simulations values for thermal conductivity of 0.419 and $3.348\left(\mathrm{~J} \mathrm{~m}^{-1} \mathrm{~s}^{-1}{ }^{\circ} \mathrm{C}^{-1}\right)$, and values for volumetric heat capacity of $1.10 \mathrm{E}+06$ and $3.10 \mathrm{E}+06\left(\mathrm{~J} \mathrm{~m}^{-3}{ }^{\circ} \mathrm{C}^{-1}\right)$ for dry and saturated sections respectively.

The first experiment involved two different simulation setups. In the first simulation setup we assigned land surface temperature as a boundary condition and observed the change in ground heat flux caused by groundwater level change within soil profile. In the second simulation setup, we applied ground heat flux as a boundary condition at land surface and observed the change in land surface temperature. The results of the two simulations suggested the indispensability of examining the effect of shallow groundwater on both temperature and ground heat flux simultaneously. To do so, it was necessary to free both of them and simulate the whole energy balance at land surface for scenarios with different groundwater levels. We accomplished that in the third experiment. All simulations were run for one year duration, after three years of pre-simulation to reach the appropriate initial boundary conditions.

\subsection{Experiments 1}

The experiment was conducted within FlexPDE environment. In one dimension soil column, heat transfer was simulated assuming conduction the only heat transport mechanism. Consequently, the sole considered governing equation was the diffusion equation:

$$
\frac{\partial\left(k_{s} \partial T\right)}{\partial^{2} z}=V H C \frac{\partial T}{\partial t}
$$

where $k_{S}$ is thermal conductivity $\left(\mathrm{J} \mathrm{m}^{-1} \mathrm{~s}^{-1}{ }^{\circ} \mathrm{C}^{-1}\right), T$ is soil temperature $\left({ }^{\circ} \mathrm{C}\right), z$ is depth $(m)$, VHC is volumetric heat capacity $\left(\mathrm{Jm}^{-3}{ }^{\circ} \mathrm{C}^{-1}\right)$ and $t$ is time $(s)$.

Analytically, yearly land surface temperature can be described by expanding equation (7) of Horton \&Wierenga, (1983) to include both the daily and the yearly cycles and by setting the depth $z$ to zero, hence:

$$
T=\bar{T}_{a v r}+A_{1} \sin \left(\frac{2 \pi t}{p_{1}}\right)+A_{2} \sin \left(\frac{2 \pi t}{p_{2}}\right)
$$


where $\bar{T}_{a v r}\left({ }^{\circ} \mathrm{C}\right)$ is the average soil temperature at all depths. $A_{1}$ and $A_{2}\left({ }^{\circ} \mathrm{C}\right)$ are the daily and yearly temperature amplitudes at land surface respectively, $p_{1}$ is one day and $p_{2}$ is one year expressed in the time unit of the equation $(s)$.

Similarly, yearly ground heat flux at land surface can be expressed by expanding equation (10) of Horton \& Wierenga (1983) to include both daily and yearly cycles and by setting the depth, $z$, to zero, thus:

$$
G=k_{s}\left[A_{1} \sqrt{\frac{2 \pi}{\alpha p_{1}}} \sin \left(\frac{2 \pi t}{p_{1}}+\frac{\pi}{4}\right)+A_{2} \sqrt{\frac{2 \pi}{\alpha p_{2}}} \sin \left(\frac{2 \pi t}{p_{2}}+\frac{\pi}{4}\right)\right]
$$

where $k_{s}\left(\mathrm{Jm}^{-1} \mathrm{~s}^{-1}{ }^{\circ} \mathrm{C}^{-1}\right)$ is average soil thermal conductivity and $\alpha\left(\mathrm{m}^{2} \mathrm{~s}^{-1}\right)$ is average thermal diffusivity.

In the first simulation, we applied land surface temperature (equation (2)) as a Dirichlet boundary condition at land surface of profiles with variant groundwater depth. As a result, FlexPDE provided the simulated ground heat flux for the different situations in terms of groundwater presence and level. Afterwards, we subtracted the resultant ground heat flux values of the profile with no-groundwater from those of profiles with groundwater and observed the differences.

On the contrary, in the second simulation we applied ground heat flux (equation (3)) as a forcing flux (Neumann boundary condition type) at land surface. Consequently, FlexPDE provided the simulated land surface temperature for the different situations in terms of groundwater presence and level. Then, we deducted the land surface temperature values of the profiles with no-groundwater from those of profiles with groundwater and observed the differences.

\subsection{Experiment 2}

To observe the thermodynamic effect of shallow groundwater on both land surface temperature and ground heat flux, all at once, we solved the complete balance system at land surface. This used SHAW to conduct this experiment because it presents heat and water transfer processes in detailed physics, besides, it has been successfully used to simulate land surface energy balance over a wide range of conditions and applications (Flerchinger and Cooley, 2000; Flerchinger et al., 2003, 2009; Flerchinger \& Hardegree, 2004; Santanello \& Friedl, 2003; Huang and Gallichand, 2006). Hereinafter, we present some of its basic features and expressions.

\subsubsection{SHAW, the simultaneous heat and water model}

The Simultaneous Heat and Water (SHAW) model is a one-dimensional soil and vegetation model that simulates the transfer of heat and water through canopy, residue, snow, and soil layers (Flerchinger, 2000). Surface energy balance and both water and heat transfer within the soil profile are expressed in SHAW as follows.

Surface energy balance is represented by the common equation:

$$
R_{n}=L E+H+G
$$

LE $\left(W m^{-2}\right)$ is latent heat flux, $H\left(W m^{-2}\right)$ is sensible heat flux and $G\left(W m^{-2}\right)$ is ground heat flux. $R_{n}\left(\mathrm{Wm}^{-2}\right)$ is the net radiation, which is the outcome of the incoming and outgoing radiation at the land surface as: 


$$
R_{n}=K_{\text {in }}-K_{\text {out }}+\varepsilon L_{\text {in }}-L_{\text {out }}
$$

$K_{\text {in }}$ and $K_{\text {out }}$ are incoming and reflected short wave radiations respectively, $\varepsilon L_{\text {in }}$ and $L_{\text {out }}$ are absorbed and emitted long wave radiations correspondingly, and $\varepsilon$ is land surface emissivity.

Sensible heat flux is calculated by:

$$
H=-\rho_{a} c_{a} \frac{\left(T_{s}-T_{a}\right)}{r_{H}}
$$

where $\rho_{a}\left(\mathrm{~kg} \mathrm{~m}^{-3}\right)$ is air density, $c_{a}\left(\mathrm{~J} \mathrm{~kg}^{-1}{ }^{\circ} \mathrm{C}^{-1}\right)$ is specific heat of air and $\mathrm{T}_{a}\left({ }^{\circ} \mathrm{C}\right)$ is air temperature at the measurement reference height $z_{\text {ref }} ; T_{s}$ is temperature $\left({ }^{\circ} \mathrm{C}\right)$ of soil surface, and $r_{H}$ is the resistance to surface heat transfer $\left(\mathrm{s} \mathrm{m}^{-1}\right)$ corrected for atmospheric stability.

Latent heat flux is computed from:

$$
L E=L \frac{\left(\rho_{v s}-\rho_{v a}\right)}{r_{v}}
$$

where $L$ is the latent heat of vaporization $\left(\mathrm{J} \mathrm{kg}^{-1}\right), E$ is vapor flux $\left(\mathrm{kg} \mathrm{s}^{-1} \mathrm{~m}^{-2}\right), \rho_{v s}$ $\left(\mathrm{kg} \mathrm{m}^{-3}\right)$ is vapor density of soil surface and $\rho_{v a}\left(\mathrm{~kg} \mathrm{~m}^{-3}\right)$ is vapor density of air at the reference height. The resistance value for vapor transfer $r_{v}\left(s \mathrm{~m}^{-1}\right)$ is taken to be equal to the resistance to surface heat transfer, $r_{H}$.

Finally, ground heat flux is expressed as:

$$
G=-k_{s} \frac{\partial T}{\partial z}
$$

where $k_{s}$ is thermal conductivity $\left(\mathrm{J} \mathrm{m}^{-1} \mathrm{~s}^{-1}{ }^{\circ} \mathrm{C}^{-1}\right)$ and $\partial \mathrm{T} / \partial z\left({ }^{\circ} \mathrm{C} \mathrm{m} \mathrm{m}^{-1}\right)$ is soil temperature gradient. Ground heat flux is computed by solving for a surface temperature that satisfies surface energy balance, which is solved iteratively and simultaneously with the equations for heat and water fluxes within the soil profile.

The governing equation for temperature variation in the soil matrix in SHAW is:

$$
V H C \frac{\partial T}{\partial t}-\rho_{i} L_{f} \frac{\partial \theta_{i}}{\partial t}=\frac{\partial\left(k_{s} \partial T\right)}{\partial^{2} z}-V H C_{W} \frac{\partial q_{l} T}{\partial z}-L\left(\frac{\partial q_{v}}{\partial z}+\frac{\partial \rho_{v}}{\partial t}\right)
$$

where $\rho_{i}$ is ice density $\left(\mathrm{kg} \mathrm{m}^{-3}\right) ; L_{f}$ is the latent heat of fusion $\left(\mathrm{J} \mathrm{kg}^{-1}\right) ; \theta_{i}$ is the volumetric ice content $\left(\mathrm{m}^{3} \mathrm{~m}^{-3}\right) ; V H C$ and $V H C_{W}$ are the volumetric heat capacity of soil matrix and water respectively $\left(\mathrm{J} \mathrm{m}^{-3} \mathrm{C}^{-1}\right) ; q_{l}$ is the liquid water flux $\left(\mathrm{ms}^{-1}\right) ; q_{v}$ is the water vapor flux $\left(\mathrm{kg} \mathrm{m}^{-2} \mathrm{~s}^{-1}\right)$ and $\rho_{v}$ is the vapor density $\left(\mathrm{kg} \mathrm{m}^{-3}\right)$.

The governing equation for water movement within soil matrix is expressed as:

$$
\frac{\partial \theta_{l}}{\partial t}+\frac{\rho_{i}}{\rho_{l}} \frac{\partial \theta_{i}}{\partial t}=\frac{\partial}{\partial z}\left[k_{h}\left(\frac{\partial \psi}{\partial z}+1\right)\right]+\frac{1}{\rho_{l}} \frac{\partial q_{v}}{\partial z}+U
$$

where $\theta_{l}$ is the volumetric liquid water content $\left(\mathrm{m}^{3} \mathrm{~m}^{-3}\right), \rho_{l}$ is the liquid water density $\left(\mathrm{kg} \mathrm{m}^{-3}\right) ; k_{h}$ is the unsaturated hydraulic conductivity $\left(\mathrm{m} \mathrm{s}^{-1}\right) ; \psi$ is the soil matric potential $(m)$ and $U$ is a source/sink term $\left(m^{3} m^{-3} s^{-1}\right)$. 
The one-dimensional state equations describing energy and water balance are written in implicit finite difference form and solved using an iterative Newton-Raphson technique for infinitely small layers.

\subsubsection{Weather and soil data}

Weather conditions above the upper boundary and soil conditions at the lower boundary define heat and water fluxes into the system. Consequently, input to the SHAW model includes daily or hourly meteorological data, general site information, vegetation and soil parameters and initial soil temperature and moisture.

The forcing weather data were obtained from Ar-Raqqa, an area in northern of Syria that characterized by steppe climate (Köppen climate classification), which is semi-dry climate with an average annual rainfall of less than $200 \mathrm{~mm}$. The simulations were run for the year 2004 after three years (2001-2003) of pre-simulation to reach appropriate initial conditions for soil profile. The daily input data includes minimum and maximum temperatures, dew point, wind speed, precipitation, and total solar radiation.

The soil for the profiles used in SHAW simulations were chosen to be standard Ottawa sand. However, since the groundwater was virtually presented within soil profile, and since the thermal properties were predefined, the type of the simulated soil is of minor importance. Basically SHAW calculates thermal conductivity and volumetric heat capacity according to the method of de Vries (de Vries, 1963). However for the sake of separating the thermodynamic effect of groundwater from the indirect one, we adjusted its FORTRAN code so the model uses the same values as used in the first experiment.

The output of the model includes surface energy fluxes, water fluxes together with temperature and moisture profiles. After solving for energy balance at the top of the different profiles, we subtracted the resultant land surface temperature, and surface heat fluxes of the no-groundwater profile from their correspondents of the profiles with the groundwater perches at $0.5,1,2$ and $3 \mathrm{~m}$.

\section{Results}

\subsection{Experiment 1}

By applying land surface temperature (equation(2)) as an upper boundary condition, then changing the thermal properties of the soil profile (due to the variation in the imaginary groundwater level), there was a considerable difference in the resultant simulated ground heat flux at land surface. The differences between ground heat flux of the no-groundwater profile and those of the profiles with different water table depths are shown in Figure 2a.

In winter, when the daily upshot of ground heat flux is usually directed upward (negative sign) and heat is escaping from the ground, ground heat flux of the profile with half meter groundwater depth was higher (in negative sign) than that of the no-groundwater profile. The difference in ground heat flux between the two profiles reached its peak value of almost $-28 \mathrm{Wm}^{-2}$ in February. The differences in ground heat fluxes between the no-groundwater profile and the profiles with groundwater at 1,2 and $3 \mathrm{~m}$ depth behaved similarly but had smaller values of the peaks and roughly one month of delay in their occurrence between one and the next.

Quite the opposite, in summer, when the daily product of ground heat flux is usually downward (positive) and earth absorbs heat, ground heat flux of the profile with groundwater at half meter depth was also higher (but in positive sign) than that of the no- 
groundwater profile, and reached similar peak value of about $28 \mathrm{Wm}^{-2}$ in August. Again, the differences in ground heat flux between the no-groundwater profile and the profiles with groundwater at 1,2 and $3 \mathrm{~m}$ depth behaved similarly with a delay in occurrence of the yet lower-values peaks.

Figure $2 \mathrm{~b}$ shows the differences among the simulated land surface temperatures resulting from applying the same values of ground heat flux (equation (3)) at the surface of the profiles with different thermal properties due to variant levels of groundwater.

In winter, land surface temperature of the profile of half meter depth of groundwater was higher than that of the no-groundwater. The difference between the two, reached its peak of about $4{ }^{\circ} \mathrm{C}$ in February. Subsequently, the differences between land surface temperature of the profiles of 1,2 and $3 \mathrm{~m}$ and that of the no-groundwater profile had lower peak values with a delay of almost a month between each other.

On the contrary, land surface temperature of the profile of half meter depth of groundwater was lower than that of no-groundwater in summer. The difference in temperature between the two profiles reached its peak value of about $4{ }^{\circ} \mathrm{C}$ in August. Again, the differences between land surface temperature of the profiles with groundwater at 1,2 and $3 \mathrm{~m}$ depth and that of the no-groundwater profile had lower peak values with a delay in their occurrence of about month between one another (Figure $2 b$ ).
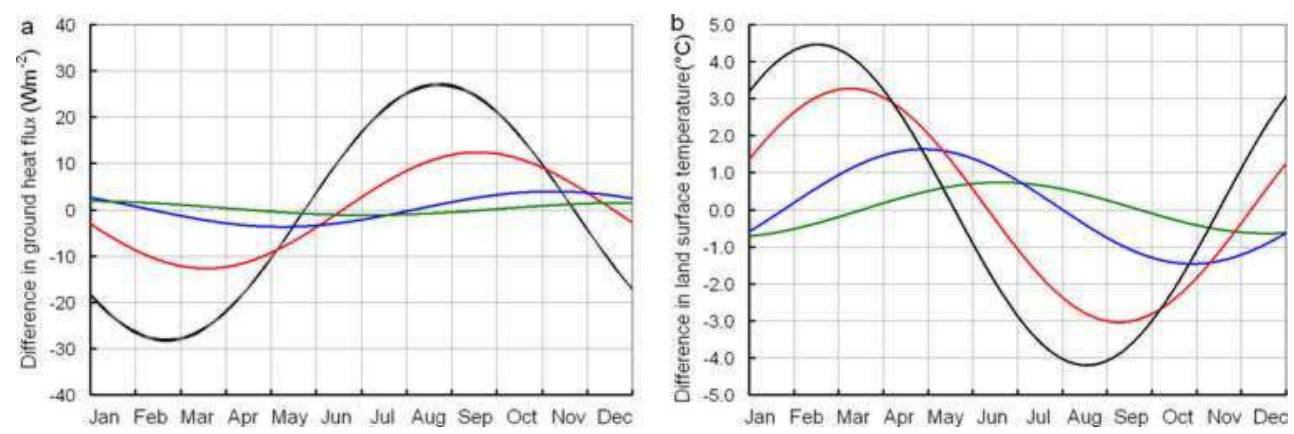

Fig. 2. a) Ground heat flux $\left(\mathrm{Wm}^{-2}\right)$ of the no-groundwater profile subtracted from those of profiles with water table depth of half meter (black), one meter (red) two meters (blue) and three meters (green). b) The same as (a) but for land surface temperature.

\subsection{Experiment 2}

With comprehensive consideration of surface energy balance and using real measured forcing data, SHAW showed more realistic results. The scattered dots in Figures 3-7 represent the differences between the no-groundwater profile and those with groundwater in terms of hourly values of the different variables which have been affected by the presence of groundwater within soil profile. The solid line drawn through the scattered dots in each figure represents the first harmonic which was computed by Fourier harmonic analysis.

Figure 3 demonstrates the surface temperature of the profile with no-groundwater subtracted from temperatures of the profiles with groundwater at $0.5,1,2$ and $3 \mathrm{~m}$ depth. Land surface temperature of the profile with groundwater at half meter depth reached a value of about $1{ }^{\circ} \mathrm{C}$ higher than that of the no-groundwater profile in winter (Figure 3a). Similarly, land surface temperatures of the profiles of 1,2 and $3 \mathrm{~m}$ groundwater-depth 
respectively reached values of roughly $0.5,0.2$ and $0.1{ }^{\circ} \mathrm{C}$ higher than that of the nogroundwater profile (Figures $3 \mathrm{~b}-3 \mathrm{~d}$ ). In summer, land surface temperature of the profiles with groundwater at depths $0.5,1,2$ and $3 \mathrm{~m}$ were lower than that of the no-groundwater profile by about $1,0.5,0.3$ and $0.2{ }^{\circ} \mathrm{C}$ respectively.
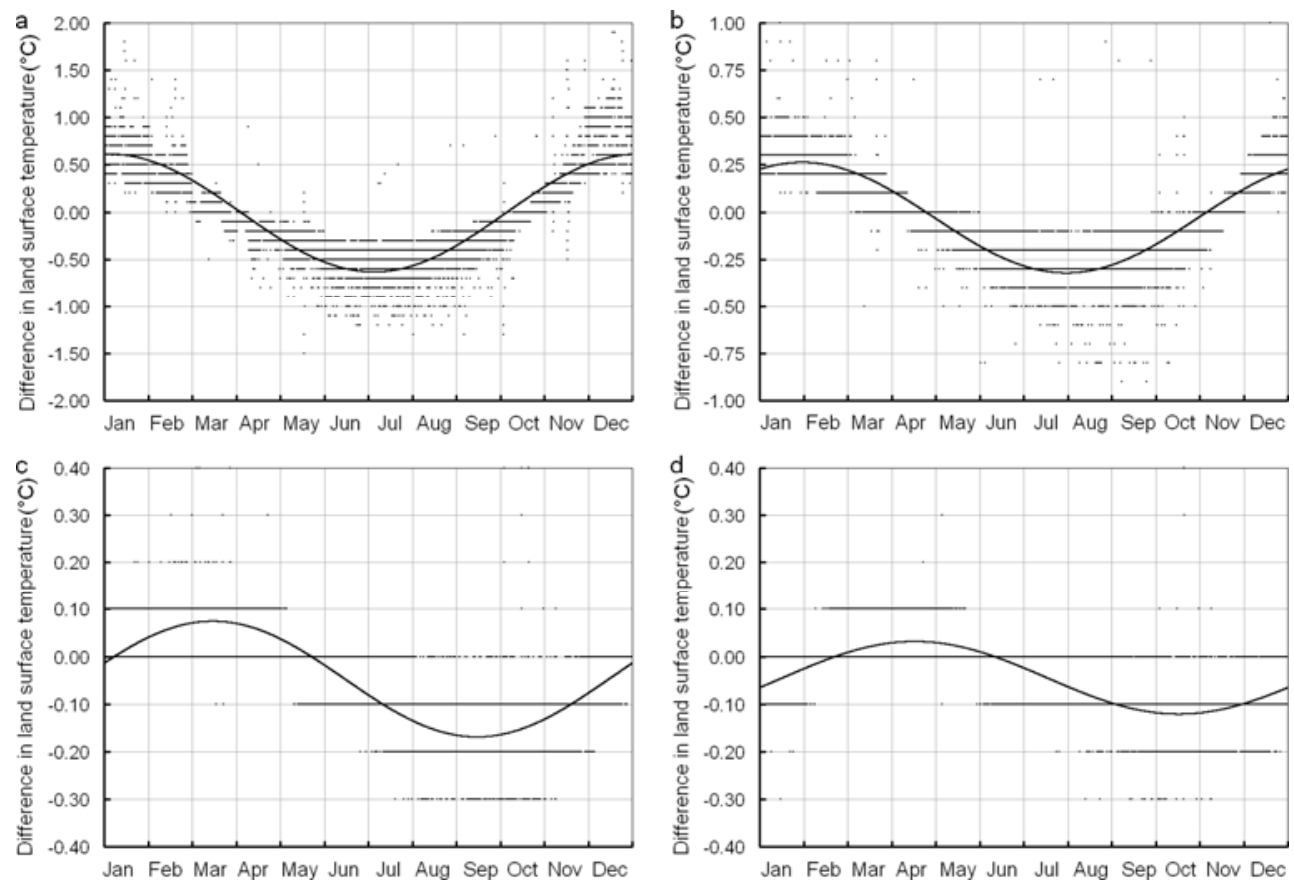

Fig. 3. Land surface temperature of the no-groundwater profile subtracted from those of profiles with groundwater at a) $0.5 m$ depth b) $1 m$ depth c) $2 m$ depth d) $3 m$ depth. Solid lines are first harmonics.

Simultaneously, ground heat flux was also influenced by the presence of groundwater as shown in Figure 4 which shows ground heat flux of the profile with no-groundwater subtracted from ground heat fluxes of the profiles with groundwater at 0.5, 1, 2 and $3 \mathrm{~m}$ depth. In wintertime, ground heat flux of the profile with half meter depth was higher (in negative sign) than that of the profile with no-groundwater by more than $11 \mathrm{Wm}^{-2}$, and also higher by about the same value (but in positive sign) in summer (Figure 4a). In the same way, ground heat fluxes of the profiles with groundwater at 1,2 and $3 \mathrm{~m}$ depth were higher than that of the no-groundwater but with smaller peak values and with shifts in the phase (Figures $4 \mathrm{~b}-4 \mathrm{~d}$ ).

Similarly, Figure 5 illustrates clear differences in sensible heat flux among the profiles of variant groundwater depths. In wintertime, sensible heat flux of the profile with groundwater at half meter depth reached a value of about $8 \mathrm{Wm}^{-2}$ higher than that of the profile with no-groundwater. Quit the opposite in summertime, sensible heat flux of the profile with groundwater at half meter depth reached a value of about the same magnitude lower than that of the profile with no-groundwater (Figure 5a). Figures 5b-5d show that 
sensible heat fluxes of the profiles with groundwater at 1, 2 and $3 m$ depth were higher than that of the no-groundwater in wintertime but with smaller magnitudes and with shifts in the phase. In summertime, sensible heat fluxes of the profiles with groundwater at 1, 2 and $3 \mathrm{~m}$ depth were lower by similar magnitudes than that of the no-groundwater.
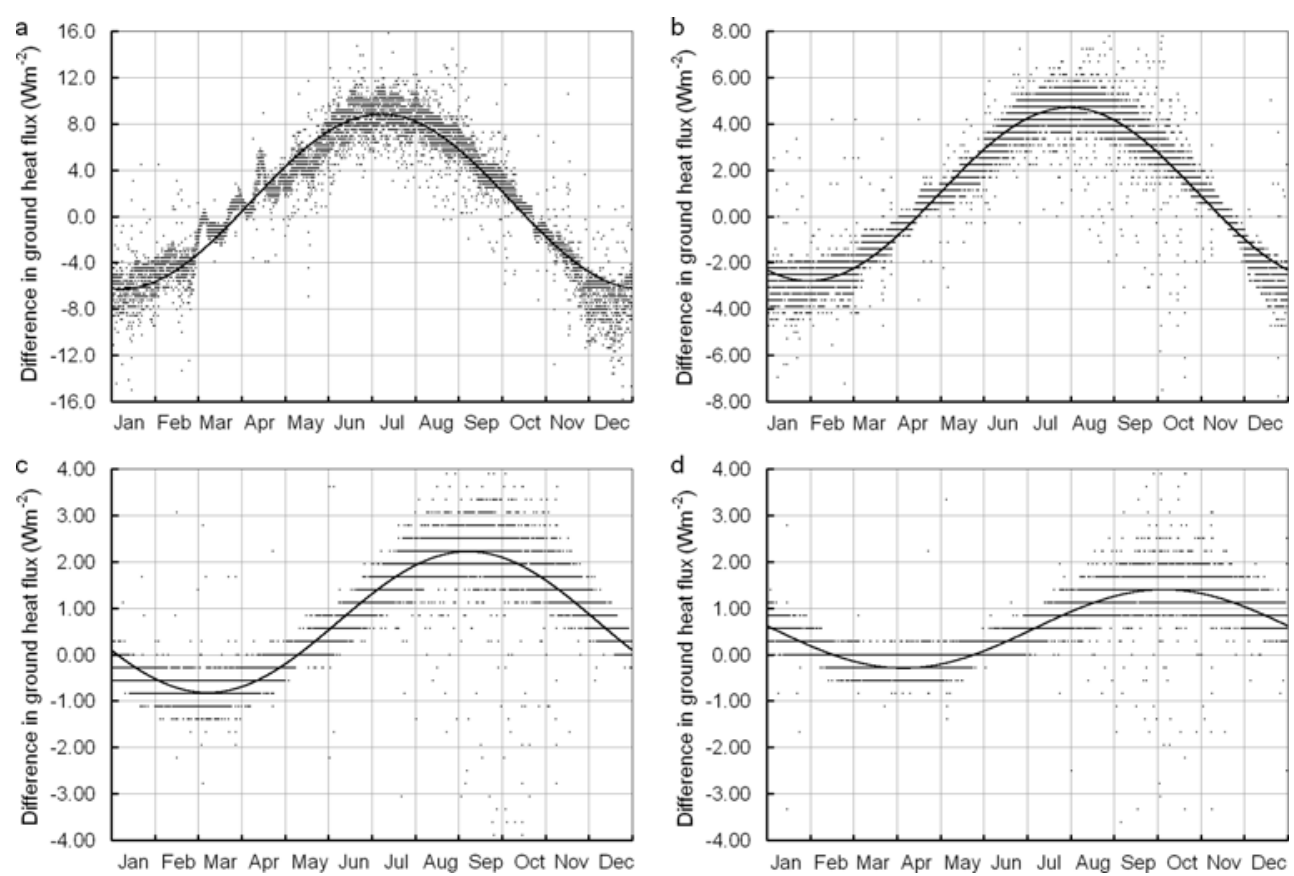

Fig. 4. Ground heat flux of the no-groundwater profile subtracted from those of profiles with groundwater at a) $0.5 m$ depth b) $1 m$ depth c) $2 m$ depth d) $3 m$ depth. Solid lines are first harmonics.

Unlike ground and sensible heat fluxes, latent heat fluxes showed very small differences among the different profiles (Figure 6). In spite of the immense amount of chaotic scattering, one can still see a small positive trend in winter and negative one in summer.

The last constituent of energy balance system which was altered by the presence of groundwater was the outgoing long-wave radiation (Figure 7). The differences looked similar to those of sensible heat flux in terms of diurnal shape and peak values but in reverse direction. Outgoing long-wave radiation of the no-groundwater profile was bigger in negative sign than that with groundwater in winter and smaller in summer.

The first harmonics sketched along of the scattered dots in Figures 3-7 demonstrated the periodic nature of the differences and were useful in pointing to the occurrence time of the differences' peaks both in winter and summer.

To have a closer look at the hourly variations (scattered dots in Figures 3-7), we zoomed in into hourly data of surface temperature and energy fluxes for two profiles: the nogroundwater profile and the profile with $50 \mathrm{~cm}$ groundwater depths within two different days (Figure 8 ). The first day was in winter (23 December, Figure 8 left side) and the second one was in summer (24 July, Figure 8 right side). 

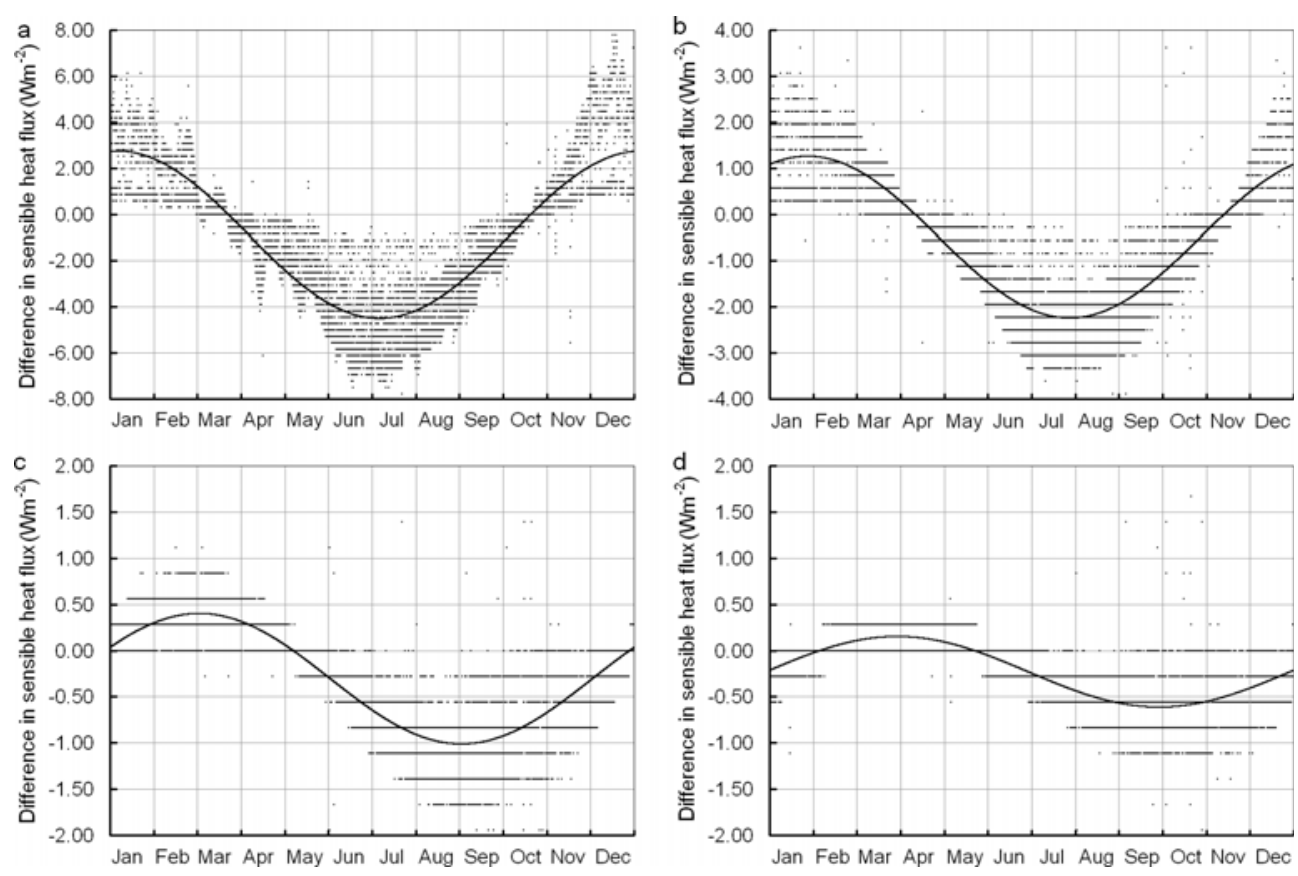

Fig. 5. Sensible heat flux of the no-groundwater profile subtracted from those of profiles with groundwater at a) $0.5 m$ depth b) $1 m$ depth c) $2 m$ depth d) $3 m$ depth. Solid lines are first harmonics.

In the winter day, land surface temperature of the no-groundwater profile was lower than that with groundwater all day long (Figure 8a). Therefore, the difference was positive. However, during nighttime the difference in land surface temperature was highest (about $1.2{ }^{\circ} \mathrm{C}$ ). During daytime when the sun radiated solar energy on land surface, the difference diminished to $0.5{ }^{\circ} \mathrm{C}$. After sunset the difference started to rise again. Oppositely, in the summer day (Figure 8b) land surface temperature of the no-groundwater profile was higher than that with the groundwater all day long; as a result, the difference was negative. Again, the difference was big at night $\left(-1^{\circ} \mathrm{C}\right)$ and moderated to $-0.4{ }^{\circ} \mathrm{C}$ in daytime hours.

Figure $8 \mathrm{c}$ illustrates that in the winter day, ground heat flux of the no-groundwater profile was smaller (in negative sign) than that of the profile with groundwater during nighttime but greater than it was (in positive sign) in daytime. Hence, the difference remained negative in sign day and night. However, the difference was larger at day than it was at night. Conversely, in the summer day (Figure 8d) ground heat flux of the no-groundwater profile was bigger (in negative sign) than that of the profile with groundwater during nighttime, but smaller than it was (in positive sign) during daytime. Hence, the difference remained positive in sign during day and night, and again the difference was larger by day than it was at night.

Sensible heat flux of the no-groundwater profile was smaller than that of the profile with groundwater during day and night in the winter day. Therefore, the difference was positive all day long (Figure 8e). However, the difference was small at night (about $1 \mathrm{Wm}^{-2}$ ) and increased during the day up to more than $6 \mathrm{Wm}^{-2}$. In contrast, in the summer day 
(Figure 8f) sensible heat flux of the no-groundwater profile was bigger than that of the profile with groundwater day and night. Therefore, the difference was negative all day long. And again the difference was small at night (about $-1 \mathrm{Wm}^{-2}$ ) and increased during the day to more than $-6 \mathrm{Wm}^{-2}$.
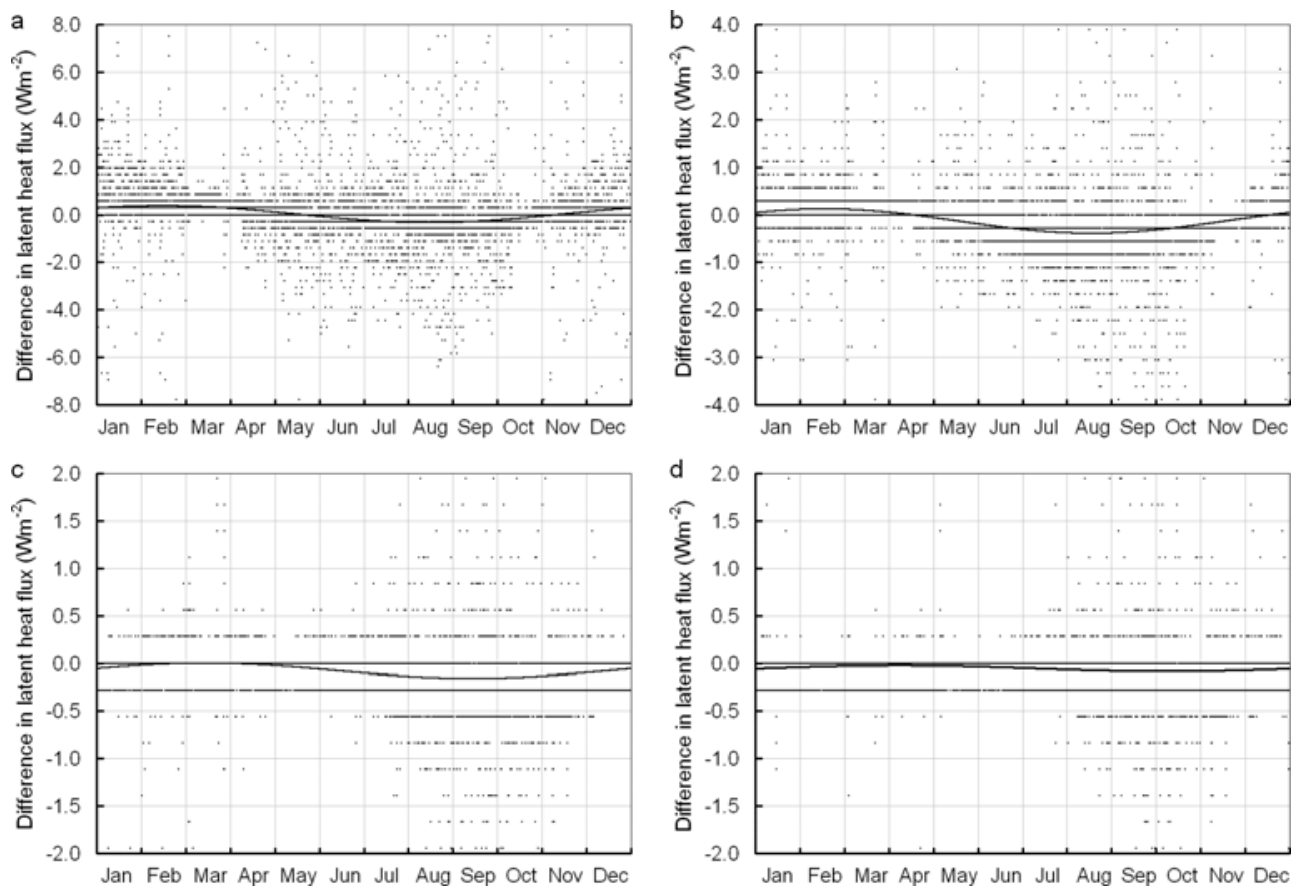

Fig. 6. Latent heat flux of the no-groundwater profile subtracted from those of profiles with groundwater at a) $0.5 m$ depth b) $1 m$ depth c) $2 m$ depth d) $3 m$ depth. Solid lines are first harmonics.

Unlike the previous two heat fluxes, latent heat flux showed very small difference between the two profiles, both in winter and summer days. In the winter day (Figure 8g) the difference in latent heat flux between the two profiles was around zero during nighttime. During daytime, latent heat flux of the profile with groundwater started to be larger than that of the no-groundwater. Oppositely, during the summer day (Figure 8h) latent heat flux of the profile with groundwater was smaller than that of the no-groundwater during daytime.

\section{Discussion}

In this study we show that the presence of groundwater within the yearly depth of heat penetration affects directly, and regardless of its effect on soil moisture above water table, both land surface temperature and ground heat flux, thereby affecting the entire surface energy balance system. The numerical experiments demonstrated that when we applied land surface temperature as a forcing upper boundary condition at land surface and 

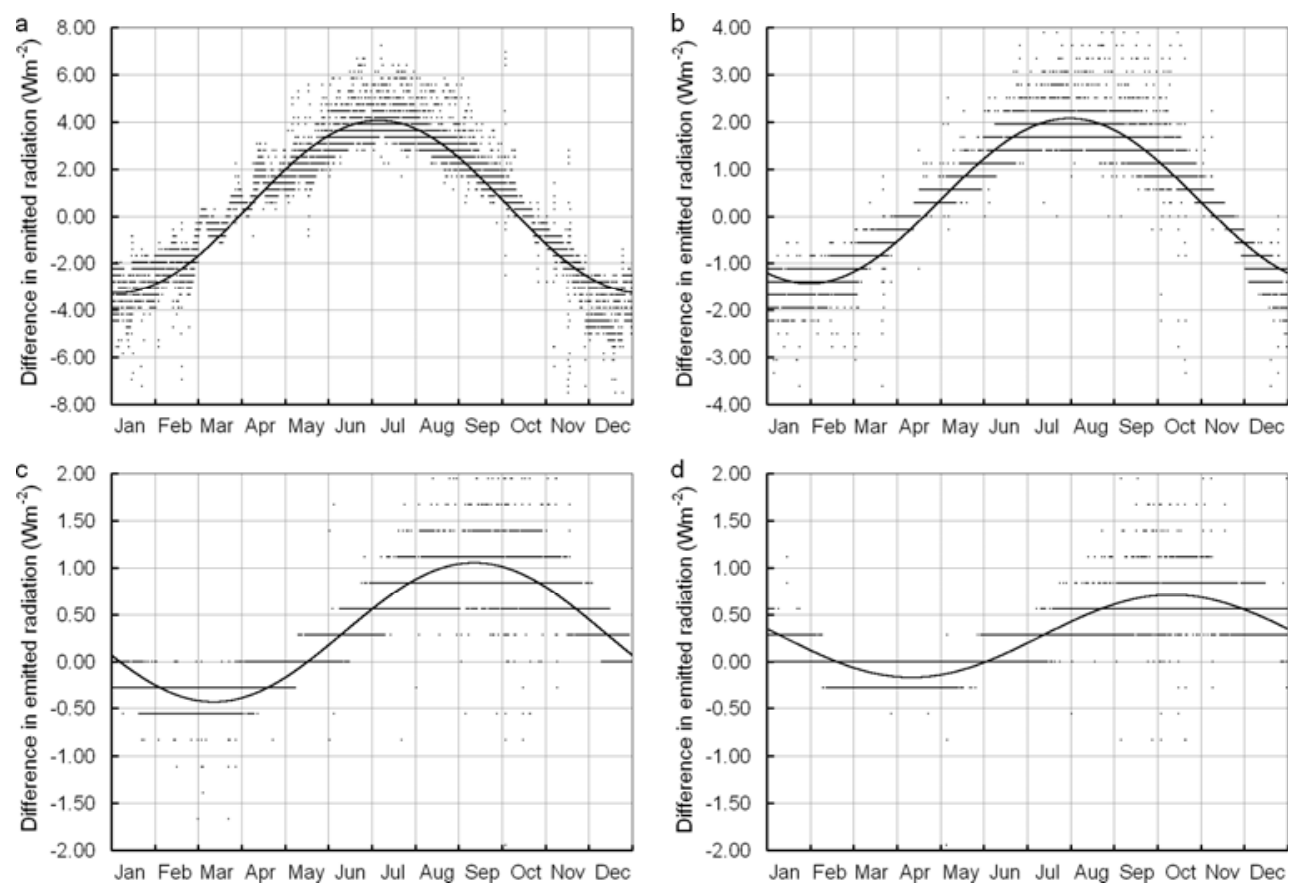

Fig. 7. Outgoing long wave radiation $\left(\mathrm{Wm}^{-2}\right)$ of the no-groundwater profile subtracted from those of profiles with groundwater at a) $0.5 \mathrm{~m}$ depth b) $1 \mathrm{~m}$ depth c) $2 \mathrm{~m}$ depth d) $3 \mathrm{~m}$ depth. Solid lines are first harmonics.

changed the water table depth, we obtained a significant difference in ground heat flux at land surface. On the contrary, when we applied forcing ground heat flux at land surface we obtained a considerable difference in land surface temperature by changing water table depth. Consequently, when we solved for the complete energy balance system at land surface, the thermodynamic effect of groundwater was demonstrated in simultaneous alteration of land surface temperature, ground heat flux, sensible heat flux, latent heat flux and outgoing long wave radiation at land surface.

The key reason behind this thermodynamic effect is the contrast in thermal properties within the soil profile. Resulting from the presence of groundwater, this contrast affects first and foremost heat penetration into the soil (equation (9)) which is chiefly pronounced via soil temperature and soil heat flux. Consequently, the largest difference should be marked for ground heat flux and land surface temperature.

When groundwater comes closer to land surface, it increases land surface temperature in winter and decreases it in summer (Figure 3). In this way it acts as a heat source in wintertime and a heat sink in summertime. As a result, shallow groundwater increases the intensity of ground heat flux both in winter and summer (Figure 4). In winter, it increases the upward ground heat flux which leads to further energy released from the ground. Contrarily, in summer it increases the downward ground heat flux allowing the earth to absorb more energy from the atmosphere. 

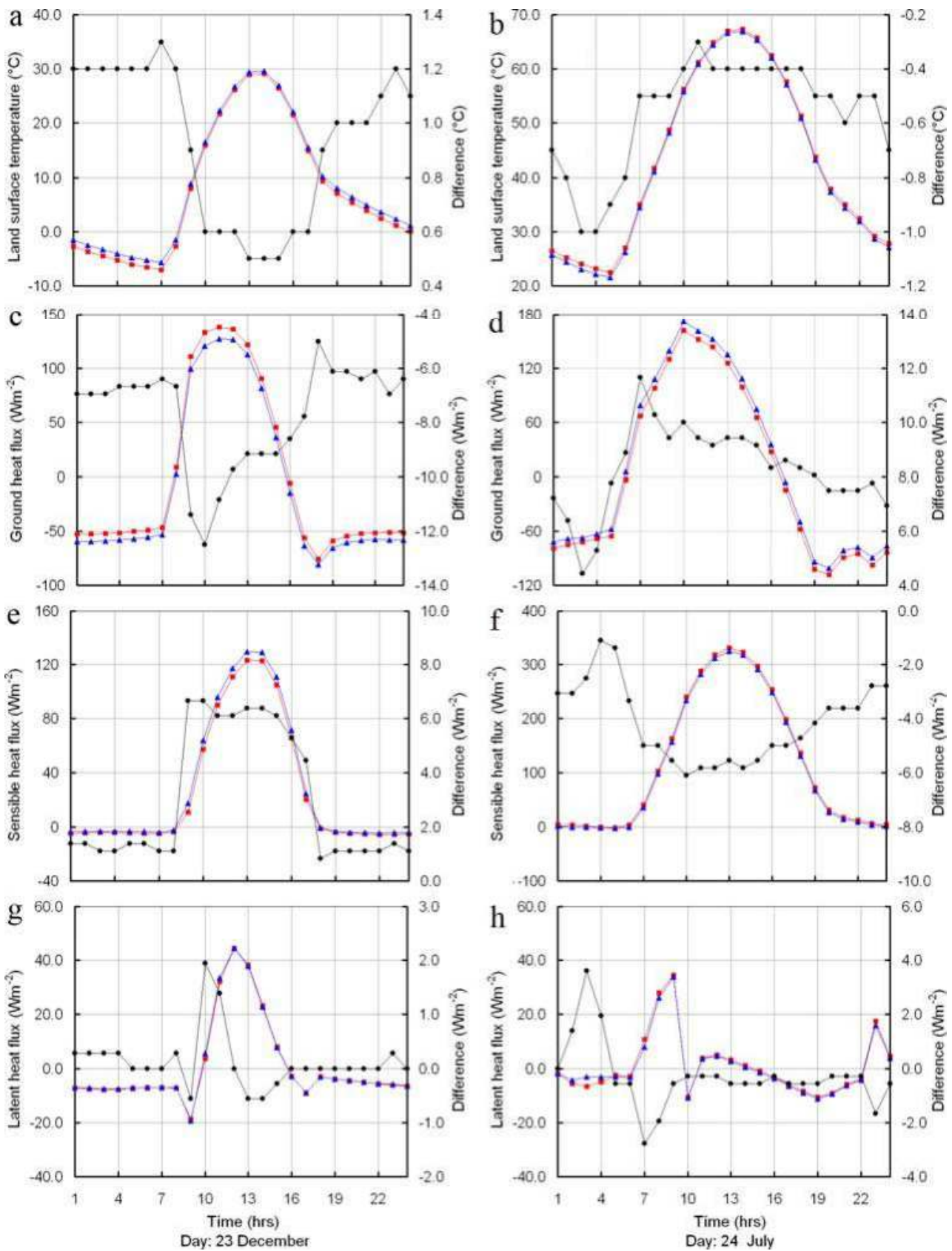

Fig. 8. Hourly values of temperature and energy fluxes of two profiles 1) with nogroundwater (red), 2) with groundwater at $50 \mathrm{~cm}$ depth (blue) and 3) the difference between them [(2)-(1)] (black), for two days: 23 Dec. (left) and 24 Jul. (right). 
In the second experiment we observed a lower magnitude of temperature difference (Figure 3) than that observed in the first experiment (Figure 2b). Actually, the difference observed of land surface temperature within the first experiment (Figure 2b) was due to the fact that land surface was the single parameter which was subject to change, since the first experiment did not take into account the entire surface energy balance system. This big difference observed in the first experiment simulations were distributed among sensible and latent heat fluxes together with emitted long-wave radiation as explained by the second experiment (Figures 5-7).

Whilst sensible heat flux mitigates land surface temperature through the reciprocal swap of heat with air above land surface, latent heat flux exploits the gained heat in more evaporation, finally, outgoing long wave radiation continuously alleviates land surface temperature by emitting energy into the atmosphere. Therefore, the increase in land surface temperature in wintertime increases the amount of energy exchange between land surface and the air above it (i.e. sensible heat flux) due to the increment in temperature contrast between both of them. Contrarily, the decrease in land surface temperature in summer decreases sensible heat flux (Figure 5). Similarly the increase in land surface temperature in winter enhances evaporation, and its decrease in summer reduces evaporation (Figure 6). Yet the effect on evaporation was the smallest. Finally the increase in land surface temperature in winter increases energy emission from soil in the form of long wave radiation, and its decrease in summer causes yet smaller amount of emission (Figure 7).

Bearing in mind the convoluted interactions among energy fluxes and radiations at land surface, it is very difficult to describe how the groundwater thermodynamically affects each of them separately. Though, if we keep in mind the instantaneous nature of those interactions, we can still furnish a simplified conception of the thermodynamic effect as illustrated in Figure 9. Since the different soil thermal properties within the soil profile alter vertical heat transfer in both vertical directions (equation (9)), ground heat flux and soil temperature are the first two components to be directly affected by the thermodynamic effect. Consequently, land surface temperature affects sensible heat flux (equation (6)), latent heat fluxes (equation (7)) and the outgoing long wave radiation. The latter affects the net radiation available for the three fluxes, hence it affects again sensible and latent heat fluxes. On the other hand, ground heat flux also affects sensible and latent heat fluxes by reducing the energy left for them from the net radiation. Obviously, incoming, reflected short-wave radiation and incoming long-wave radiation stay outside the thermodynamic effect of groundwater.

The small difference in latent heat flux compared to the difference in other fluxes (Figure 6) can be justified by two reasons: Firstly, latent heat flux was originally small in this experiment due to the dry conditions in the considered area, and secondly, latent heat flux, unlike ground and sensible heat fluxes, is not a main function of land surface temperature; Whereas ground heat flux is a key function of land surface temperature and temperature of the soil beneath (equation (8)), and sensible heat flux is a primary function of land surface temperature and temperature of the air above (equation (6)), latent heat flux is a function of vapor density contrast between land surface and the atmosphere (equation (7)), and not a primary function of land surface temperature.

When groundwater depth increased, it was observed that the differences' peaks experienced a delay of about a month between one depth and the next (Figures 1-7). Similarly, it was also observed that the differences' peaks had lower values when groundwater went deeper. 
The delay and the lower values can be justified by the fact that the closer the groundwater is to land surface the stronger and sooner its effect takes place on the penetrated ground heat flux.

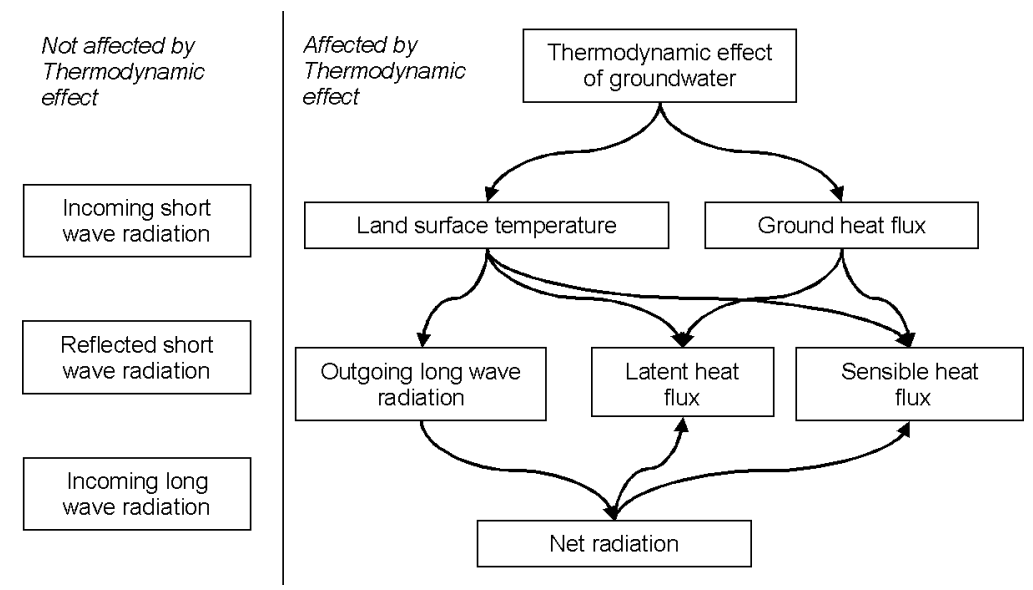

Fig. 9. Schematic description of groundwater thermodynamic effect on land surface temperature and the different components of surface energy balance.

The first experiment was simple and could not be compared to real world; therefore the observed differences in Figures $2 \mathrm{a}$ and $2 \mathrm{~b}$ were sketched by neat lines without hourly fluctuations. On the contrary, the simulations in the second experiment were closer to reality and produced hourly variations presented by the scattering dots around the first harmonic lines within Figures 3-7. Samples of such hourly variations were presented in Figure 8. In both winter and summer days, the difference in land surface temperature was highest during nighttime and decreased in the daytime (Figures $8 \mathrm{a}$ and $8 \mathrm{~b}$ ). That was due to the fact that sensible and latent heat fluxes were stronger during daytime and had small magnitude during nighttime, in this way, they reduced the difference in land surface temperature in daytime in favor of their own differences (Figures 8e-8h).

In contrary to land surface temperature difference behavior, the difference in ground heat flux had high values in the night and had even higher values in daytime. This is explained by that the earth subsurface is the primary source of energy that drives the upward ground heat flux during nighttime, on the other hand, during daytime solar radiation provides the earth with higher amounts of energy and makes the difference in downward ground heat flux more pronounced (Figures 8c and 8d).

Alongside the normal scattering around the first harmonic lines in Figures 3-7 which presents hourly fluctuations, some outliers have been noticed. Investigating these outliers illuminated that these outliers result from the size of time-step ( 1 hour) used in SHAW simulations. While this can be enhanced by using smaller time step, this will require extensive simulation and numerical exertion.

In general we found that the magnitude of the thermodynamic effect on land surface temperature and surface energy balance system was small, but when considering the indirect effect, there will be two possibilities: 1) the two effects work in the same direction, then the thermodynamic effect will increase the intensity of the comprehensive effect, or 2) 
the two effects work in opposite directions and then the thermodynamic effect will decrease the intensity of the comprehensive effect. In this way, highlighting this aspect of groundwater effect was necessary to complete the view. As a result, it is important to study the comprehensive effect. The latter effect was studied in details by Alkhaier et al. (2011a) who took into consideration majority of the aspects through which shallow groundwater affects land surface temperature and the various components of surface energy balance system.

The recent advancement in the field of remote sensing models, e.g. Surface Energy Balance System (SEBS) (Su, 2002; van der Kwast et al., 2009; Ma et al., 2011) and Surface Energy Balance Algorithm for Land (SEBAL) (Bastiaanssen, 1995; Mohamed et al., 2004; Zwart \& Bastiaanssen, 2006), has proved that satellite imagery is valuable tool in retrieving major components of surface energy balance both in day and night. With the aid of the findings in this study, together with those of the comprehensive effect of groundwater (Alkhaier et al., 2011a), one can think of utilizing those models in mapping the areal extents and depths to shallow groundwater. The best time of the year to detect that effect is most likely winter and summer time, bearing in mind the delay in the peaks' occurrence with different depths of groundwater as explained above. For the best time within a day, it is advised to investigate within the daytime hours for the difference in ground heat flux and sensible heat flux and to a minor extent for the difference in latent heat flux. Within the nighttime hours it is advised to explore the difference in land surface temperature and ground heat flux.

In a recent study, Alkhaier et al. (2011b) inspected the capacity of MODIS (Moderateresolution Imaging Spectroradiometer), a scientific instrument on board of two currently operational satellites (Terra and Aqua), to detect the comprehensive effect of shallow groundwater on land surface temperature. Also they inspected the general features of spatial effect of shallow groundwater on surface soil moisture, surface soil temperature and surface energy balance components, at the time of image acquisition.

\section{Conclusions}

In summary, we conclude that shallow groundwater - regardless of its indirect effect generated via its effect on soil moisture above water table - does indeed affect directly the components of the energy balance system at land surface by its distinctive thermal properties. This thermodynamic effect is primarily obvious on land surface temperature, ground heat flux, sensible heat flux and outgoing long-wave radiation.

In terms of seasonally prospective, the thermodynamic effect on all these components is mostly pronounced in winter and summer. Whereas, in terms of hourly prospective, the difference in land surface temperature and outgoing long wave radiation is higher during nighttime, and the difference in ground and sensible heat fluxes is higher during daytime.

In spite of its small magnitudes, highlighting the different features of the thermodynamic effect is important to make the understanding of the comprehensive effect of groundwater more complete. The importance of the thermodynamic effect comes from its interaction with the indirect effect which originates from soil moisture above water table; this interaction may increase or decrease the upshot of the total effect.

Finally, it is important to give emphasis to the fact that in this study we separated numerically the thermodynamic effect from the indirect effect of groundwater on land surface and surface energy balance system. However, in real world these two effects can not be separated naturally and the image can not be complete without considering the 
combined effect. Nevertheless, this thermodynamic effect on land surface has not been established before and it clearly offers a more clear view of groundwater effect which is promising for enhancing the related surface energy balance studies and remote sensing applications.

\section{References}

Alkhaier, F., Schotting, R. J., \& Su, Z. (2009). A qualitative description of shallow groundwater effect on surface temperature of bare soil. Hydrology and Earth System Sciences, Vol. 13, pp. 1749-1756.

Alkhaier, F., Flerchinger, G. N., \& Su, Z. (2011a). The effect of shallow groundwater on land surface temperature and surface energy balance under the conditions of bare soil, I. Modeling and Description, under review.

Alkhaier, F., Flerchinger, G. N., \& Su, Z. (2011b). The effect of shallow groundwater on land surface temperature and surface energy balance under the conditions of bare soil, II. Utilizing remote sensing in featuring that effect, under review.

Bastiaanssen, W. G. M. (1995). Regionalization of surface flux densities and moisture indicators in composite terrain - A remote sensing approach under clear skies in Mediterranean climates, Ph.D. Thesis, 273 pp., Wageningen Agricultural University, the Netherlands.

Bense, V. F., \& Kooi, H. (2004). Temporal and spatial variations of shallow subsurface temperature as a record of lateral variations in groundwater flow. Journal of Geophysical Research, Vol. 109, B04103, doi:10.1029/2003JB002782.

Birman, H. (1969). Geothermal exploration for groundwater. Geological Society of America Bulletin, Vol. 80, No. 4, pp. 617-630.

Cartwright, K. (1968). Thermal prospecting for groundwater. Water Resources Research, Vol. 4, No. 2, pp. 395-401.

Cartwright, K. (1974). Tracing shallow groundwater systems by soil temperatures. Water Resources Research, Vol. 10, No. 4, pp. 847-855.

Chen, X., \& Hu, Q. (2004). Groundwater influences on soil moisture and surface evaporation. Journal of Hydrology, Vol. 297, pp. 285-300.

de Vries, A. D. (1963). Thermal properties of soils, In: Physics of plant environment, pp. 210235, North Holland Publication Company, Amsterdam, the Netherlands.

Fan, Y., Miguez-Macho, G., Weaver, C. P., Walko, R., \& Robock, A. (2007). Incorporating water table dynamics in climate modeling: I. Water table observations and equilibrium water table simulations. Journal of Geophysical Research, Vol. 112, D10125, doi:10.1029/2006JD008111.

Flerchinger, G. N. (2000). The simultaneous heat and water (SHAW) model, Technical Report, 37 pp., Northwest Watershed Research Centre, USDA Agricultural Research Service, Boise, Idaho.

Flerchinger, G. N., \& Cooley, K. R. (2000). A ten-year water balance of a mountainous semiarid watershed. Journal of Hydrology, Vol. 237, pp. 86-99.

Flerchinger, G. N., \& Hardegree, S. P. (2004). Modelling near-surface soil temperature and moisture for germination response predictions of post-wildfire seedbeds. Journal of Arid Environments, Vol. 59, pp. 369-385, doi:10.1016/j.jaridenv.2004.01.016.

Flerchinger, G. N., Sauer, T. J., \& Aiken, R. A. (2003). Effects of crop residue cover and architecture on heat and water transfer at the soil surface. Geoderma, Vol. 116, pp. 217-233, doi:10.1016/S0016-7061(03)00102-2. 
Flerchinger, G. N., Xiao, W., Sauer, T. J., \& Yu, Q. (2009). Simulation of within-canopy radiation exchange. NJAS -Wageningen Journal of Life Sciences, Vol. 57, pp. 5-15.

Furuya, G., Suemine, A., Sassa, K., Komatsubara, T., Watanabe, N., \& Marui, H. (2006). Relationship between groundwater flow estimated by soil temperature and slope failures caused by heavy rainfall, Shikoku Island, south western Japan. Engineering Geology, Vol. 85, pp. 332-346, doi:10.1016/j.enggeo.2006.03.002.

Gulden, L. E., Rosero, E., Yang, Z., Rodell, M., Jackson, C. S., Niu, G., Yeh, P. J.-F., \& Famiglietti, J. (2007). Improving land-surface model hydrology: Is an explicit aquifer model better than a deeper soil profile?. Geophysical Research Letters, Vol. 34, L09402, doi:10.1029/2007GL029804.

Heilman, J. L., \& Moore, D. G. (1982). Evaluating depth to shallow groundwater using heat capacity mapping mission (HCMM) data. Photogrammetric Engineering and Remote Sensing, Vol. 48, No. 12, pp. 1903-1906.

Horton, R., \& Wierenga, P. J. (1983). Estimating the soil heat flux from observations of soil temperature near the surface. Soil Science Society of America, Vol. 47, pp. 14-20.

Huang, M., \& Gallichand, J. (2006). Use of the SHAW model to assess soil water recovery after apple trees in the gully region of the Loess Plateau, China. Agricultural Water Management, Vol. 85, pp. 67-76, doi:10.1016/j.agwat.2006.03.009.

Huntley, D. (1978). On the detection of shallow aquifers using thermal infrared imagery. Water Resources Research, Vol. 14, No. 6, pp. 1075- 1083.

Jiang, X., Niu, G.-Y., \& Yang, Z.-L. (2009). Impacts of vegetation and groundwater dynamics on warm season precipitation over the Central United States. Journal of Geophysical Research, Vol. 114, D06109, doi:10.1029/2008JD010756.

Kappelmeyer, O. (1957). The use of near surface temperature measurements for discovering anomalies due to causes at depths. Geophysical Prospective, Vol. 5, No. 3, pp. 239258.

Liang X., \& Xie, Z. (2003). Important factors in land-atmosphere interactions: surface runoff generations and interactions between surface and groundwater. Global and Planetary Change, Vol. 38, pp. 101-114.

Lo, M-H., Yeh, P. J.-F., Famiglietti, J. S. (2008). Constraining water table depth simulations in a land surface model using estimated baseflow, Advances in Water Resources, Vol. 31, No. 12, pp. 1552-1564, ISSN 0309-1708, doi: 10.1016/j.advwatres.2008.06.007.

Ma, W., Ma, Y. \& Su, Z. (2011). Feasibility of retrieving land surface heat fluxes from ASTER data using SEBS: a case study from the Namco area of the Tibetan plateau. Arctic, Antarctic, and Alpine Research, Vol. 43, No. 2, pp. 239-245.

Mohamed, Y. A., Bastiaanssen, W. G. M. \& Savenije, H. H. G. (2004). Spatial variability of evaporation and moisture storage in the swamps of the upper Nile studied by remote sensing techniques. Journal of Hydrology., Vol. 289, pp. 145-164.

Myers, V. I., \& Moore D. G. (1972). Remote sensing for defining aquifers in glacial drift, Proceedings of Eighth International Symposium on Remote Sensing of Environment, Vol. 1, pp. 715-728, University of Michigan, October 1972.

Niu, G.-Y., Yang, Z.-L., Dickinson, R. E., Gulden, L. E., \& Su, H. (2007). Development of a simple groundwater model for use in climate models and evaluation with Gravity Recovery and Climate Experiment data. Journal of Geophysical Research., Vol. 112, D07103, doi:10.1029/2006JD007522. 
Quiel, F. (1975). Thermal/IR in geology. Photogrammetric Engineering and Remote Sensing, Vol. 41, No. 3, pp. 341-346.

Santanello, J. A., \& Friedl, M. A. (2003). Diurnal covariation in soil heat flux and net radiation. Journal of Applied Meteorology, Vol. 42, pp. 851-862.

$\mathrm{Su}, \mathrm{Z}$. (2002). The Surface Energy Balance System (SEBS) for estimation of turbulent heat fluxes. Hydrology and Earth System Sciences, Vol. 6, No. 1, pp. 85-99.

van der Kwast, J., et al. (2009). Evaluation of the surface energy balance system SEBS applied to ASTER imagery with flux measurements at the SPARC 2004 site, Barrax, Spain. Hydrology and Earth System Sciences, Vol. 13, No. 7, pp. 1337-1347.

Yeh, P. J-F., \& Eltahir, E. A. B., (2005). Representation of Water Table Dynamics in a Land Surface Scheme. Part I: Model Development. Journal of Climate, Vol. 18, pp. 18611880, doi: 10.1175/JCLI3330.1

York, J. P, Person, M., Gutowski, W. J., \& Winter, T. C. (2002). Putting aquifers into atmospheric simulation models: an example from the Mill Creek watershed, northeastern Kansas. Advances in Water Resources, Vol. 25, pp. 221-238.

Zwart, S. J., \& Bastiaanssen, W. G. M. (2006). SEBAL for the description of spatial variability of water productivity in various wheat systems. Agricultral Water Management, Vol. 89, pp. 287-296. 


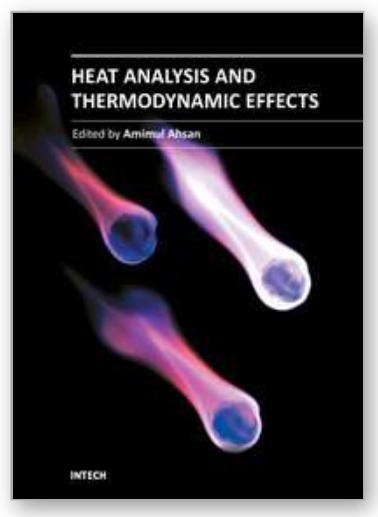

\author{
Heat Analysis and Thermodynamic Effects \\ Edited by Dr. Amimul Ahsan
}

ISBN 978-953-307-585-3

Hard cover, 394 pages

Publisher InTech

Published online 22, September, 2011

Published in print edition September, 2011

The heat transfer and analysis on heat pipe and exchanger, and thermal stress are significant issues in a design of wide range of industrial processes and devices. This book includes 17 advanced and revised contributions, and it covers mainly (1) thermodynamic effects and thermal stress, (2) heat pipe and exchanger, (3) gas flow and oxidation, and (4) heat analysis. The first section introduces spontaneous heat flow, thermodynamic effect of groundwater, stress on vertical cylindrical vessel, transient temperature fields, principles of thermoelectric conversion, and transformer performances. The second section covers thermosyphon heat pipe, shell and tube heat exchangers, heat transfer in bundles of transversely-finned tubes, fired heaters for petroleum refineries, and heat exchangers of irreversible power cycles. The third section includes gas flow over a cylinder, gas-solid flow applications, oxidation exposure, effects of buoyancy, and application of energy and thermal performance index on energy efficiency. The forth section presents integral transform and green function methods, micro capillary pumped loop, influence of polyisobutylene additions, synthesis of novel materials, and materials for electromagnetic launchers. The advanced ideas and information described here will be fruitful for the readers to find a sustainable solution in an industrialized society.

\title{
How to reference
}

In order to correctly reference this scholarly work, feel free to copy and paste the following:

F. Alkhaier, G. N. Flerchinger and Z. Su (2011). The Thermodynamic Effect of Shallow Groundwater on Temperature and Energy Balance at Bare Land Surface, Heat Analysis and Thermodynamic Effects, Dr. Amimul Ahsan (Ed.), ISBN: 978-953-307-585-3, InTech, Available from:

http://www.intechopen.com/books/heat-analysis-and-thermodynamic-effects/the-thermodynamic-effect-ofshallow-groundwater-on-temperature-and-energy-balance-at-bare-land-surfa

\section{INTECH}

open science | open minds

\section{InTech Europe}

University Campus STeP Ri

Slavka Krautzeka 83/A

51000 Rijeka, Croatia

Phone: +385 (51) 770447

Fax: +385 (51) 686166

\section{InTech China}

Unit 405, Office Block, Hotel Equatorial Shanghai

No.65, Yan An Road (West), Shanghai, 200040, China 中国上海市延安西路65号上海国际贵都大饭店办公楼 405 单元

Phone: +86-21-62489820

Fax: +86-21-62489821 
www.intechopen.com 
(C) 2011 The Author(s). Licensee IntechOpen. This chapter is distributed under the terms of the Creative Commons Attribution-NonCommercialShareAlike-3.0 License, which permits use, distribution and reproduction for non-commercial purposes, provided the original is properly cited and derivative works building on this content are distributed under the same license. 